\title{
ANATOMIA FOLIAR DE QUATRO ESPÉCIES DO GÊNERO CATTLEYA LINDL. (ORCHIDACEAE) DO PLANALTO CENTRAL BRASILEIRO ${ }^{1}$
}

\author{
Rosane Zanenga-Godoy ${ }^{2}$ \\ Cecilia Gonçalves Costa ${ }^{3}$
}

Recebido em 20/09/2001. Aceito em 28/05/2002

\begin{abstract}
RESUMO - (Anatomia foliar de quatro espécies do gênero Cattleya Lindl. (Orchidaceae) do Planalto Central Brasileiro). As espécies analisadas (Cattleya araguaiensis Pabst, C. bicolor Lindl., C. nobilior Rchb. e C. walkeriana Gardn.) apresentam epiderme uniestratificada em ambas as faces da lâmina foliar, ocorrendo estômatos na face abaxial; deposição de cera epicuticular em crostas, escamas, flocos e plaquetas; em C. araguaiensis ocorrem estegmatas incrustados nas células epidérmicas; em todas as espécies ocorre hipoderme com células de paredes espessadas; mesofilo bifacial, compacto; células paliçádicas atípicas, com barras de espessamento; feixes vasculares colaterais dispostos alternadamente, acompanhados por bainha de fibras; cordões fibrosos acompanhados por estegmatas ocorrem longitudinalmente na lâmina foliar; presença de ráfides. Os aspectos descritos revelam acentuada xeromorfia, em função de economia de água.
\end{abstract}

Palavras-chave - Orchidaceae, Cattleya, anatomia foliar, epifitismo

\begin{abstract}
Foliar anatomy of four species of genus Cattleya Lindl. (Orchidaceae) of the Brazilian Central Planalt). The analyzed species (Cattleya araguaiensis Pabst, C. bicolor Lindl., C. nobilior Rchb. e C. walkeriana Gardn.) present unistratified epidermis at both surfaces with stomata at abaxial surface; deposition of epicuticular wax in crusts, scales, granules and plates; $C$. araguaiensis presents stegmata at epidermal cells; others characteristics present at all species are: hypodermis cells with thick walls; bifacial and compact mesophyll; atipic cells of palisade parenchyma with thichness bars; collateral vascular bundles alternate accompanied by sheath fibers; cordon fibers accompanied by stegmata in the foliar blade; raphids. The described aspects reveal accentuate xeromorphy for water economy.
\end{abstract}

Key words - Orchidaceae, Cattleya, leaf anatomy, epiphytism

1 Parte da Dissertação de Mestrado da primeira Autora

Professora da Secretaria de Educação, SHI Q1 01 - Casa 16, CEP 71505-010, Brasília, DF, Brasil (rzgodoy@globo.com.br)

3 Instituto de Pesquisa, Área de Botânica Estrutural, Jardim Botânico do Rio de Janeiro, Bolsista CNPq, Rua Pacheco Leão, 915, CEP 22460-030, Rio de Janeiro, RJ, Brasil (ccosta@jbrj.goc.br) 


\section{Introdução}

As Orchidaceae representam o grupo mais evoluído da super ordem Liliiflorae e constituem uma das maiores famílias do Reino Vegetal, com aproximadamente 30.000 espécies (Cronquist 1981). O gênero Cattleya, com cerca de 60 espécies de ervas epífitas que vivem nas matas (Pabst \& Dungs 1975), é considerado pequeno no contexto geral da família (Cronquist $l$. c.). Segundo Filgueiras \& Pereira (1990), três espécies do gênero ocorrem no Distrito Federal: Cattleya bicolor Lind1., C. nobilior Rchb. e C. walkeriana Gardn. Bianchetti (comunicação pessoal) informa ainda a ocorrência de uma quarta espécie no Planalto Central, C. araguaiensis Pabst.

A família tem características muito especializadas, que lhe confere elevado poder de adaptação a diferentes ambientes (Benzing et al. 1982) e suas flores exibem particularidades marcantes que desempenham importante papel na atração do agente polinizador o que, conseqüentemente, favorece a polinização cruzada (Dressler 1993).

No conceito de Olatunji \& Nengim (1980), as orquídeas epífitas representam o grupo de plantas mais especializado sob o ponto de vista ecológico, visto que requerem adaptações morfológicas e funcionais que lhes permitem sobreviver em ambientes xerofíticos, garantindolhes a absorção e a conservação eficientes de nutrientes e água, além de lhes proporcionar fixação. Os pseudobulbos, o velame das raízes aéreas, a ocorrência de células com barras de espessamento no mesofilo e o metabolismo CAM são adaptações estruturais e fisiológicas altamente eficientes na biologia destas plantas (Scatena \& Nunes 1996; Oliveira \& Sajo 1999).

Vale ressaltar ainda que as espécies de Cattleya e de outros gêneros da família são muito utilizadas no mundo inteiro como plantas ornamentais pela beleza de suas flores (Bechtel et al. 1992), o que lhes confere considerável importância econômica.
Entretanto, as referências sobre a anatomia das espécies de Cattleya são escassas, além do que os dados disponíveis na literatura sobre as orquídeas do Planalto Central brasileiro são mais escassos ainda.

Este trabalho tem por objetivos: descrever a anatomia foliar das espécies de Cattleya do Planalto Central brasileiro; analisar as influências ambientais sobre a estrutura foliar dessas espécies e verificar as possíveis implicações taxonômicas das características analisadas.

\section{Material e métodos}

As espécies em estudo foram coletadas em seu habitat natural, na época de floração. Cattleya bicolor Lindl. foi coletada na Reserva Ecológica do Guará, situada a $15^{\circ} 48^{\prime} \mathrm{S}$ e $47^{\circ}$ 58'O; Cattleya walkeriana Gardn., na Fazenda Dois Irmãos, localizada entre $15^{\circ} 30^{\prime}$ e $15^{\circ} 40^{\prime}$ Sul e $47^{\circ} 50^{\prime}$ e $48^{\circ} 12^{\prime} \mathrm{O}$ e Cattleya nobilior Rchb. a $240 \mathrm{~km}$ de Brasília, na Cidade de Flores (Estado de Goiás), situada a $15^{\circ} 48^{\prime} \mathrm{S}$ e $47^{\circ} 58^{\prime}$. As amostras de Cattleya araguaiensis Pabst foram provenientes de coletas realizadas às margens do Rio Araguaia.

Foram selecionadas folhas completamente expandidas, das quais destacaram-se fragmentos da base, terço médio (nervura mediana, região intercostal e bordo) e ápice, para fixação em FAA 50 (formaldeído 37-40\%, ácido acético glacial e álcool etílico 50\% 1:1:18, v/v), segundo Johansen (1940), por 48 horas no vácuo. O material foi submetido aos procedimentos usuais em microtécnica vegetal (Sass 1951) e, após inclusão em parafina histológica, foi secionado ao micrótomo rotativo Spencer, na espessura média de $10 \mu \mathrm{m}$. Obtiveram-se secções nos planos transversal e longitudinal, que foram submetidas ao processo de coloração dupla Astra Blau x Fucsina Básica (Roeser 1972 apud Kraus \& Arduin 1997), que se revelou mais apropriado ao material.

A contagem estomática foi efetuada na região intercostal da lâmina foliar (base, meio e 
ápice), em fragmentos de folhas dissociadas segundo o método de Jeffrey (Johansen 1940), contando-se 15 campos para cada espécie, em cada uma das regiões mencionadas. A comparação dos dados de densidade estomática foi realizada pelo método de Student-NewmanKeuls com nível de significância de 0,05 . Os padrões dos estômatos e da cera epicuticular foram descritos segundo os parâmetros propostos por Wilkinson (1988).

A cutícula, sua ornamentação e o padrão de deposição da cera foram observados sob microscopia óptica (MO) e eletrônica de varredura (MEV). Para as observações ao MEV, fragmentos de folhas desidratadas foram submetidos ao ponto crítico e vaporizados com ouro. Utilizaram-se dois grupos amostrais para observação da cera - com e sem tratamento (Gunning \& Steer 1985). O material do primeiro grupo foi imerso em clorofórmio por 18 horas (Norris \& Bukovac 1968) e depois submetido aos demais procedimentos.

A fim de proceder à análise dos feixes vasculares, acompanhou-se seu percurso da bainha até a região apical da lâmina foliar e para dissociação dos elementos celulares, empregou-se o método de Jeffrey (Johansen 1940).

Os testes microquímicos foram realizados em seções obtidas à mão-livre, com auxílio de lâmina de barbear, em material não fixado. A ocorrência de mucilagem foi detectada pelo vermelho de rutênio (Strasburger 1924); corpos silicosos e substâncias fenólicas foram evidenciados, respectivamente, com o uso de cristais de fenol e cloreto férrico; a cutina, pelo Sudan IV (Johansen 1940); a lignina foi testada com floroglucina em meio ácido; os cloroplastídeos foram evidenciados pela hematoxilina; o amido, pelo lugol (Sass 1951); celulose e lignina, diferenciadas pelo cloreto de zinco iodado (Purvis 1962 apud Kraus \& Arduin 1997) e o oxalato de cálcio foi revelado pela ação dos ácidos acético glacial, clorídrico 10\% e nítrico 10\% (Kraus \& Arduin 1997).
Os desenhos foram feitos em câmara clara acoplada ao microscópio de luz; as fotomicrografias, obtidas ao fotomicroscópio Zeiss modelo Axioskop e as eletromicrografias, com o microscópio eletrônico de varredura JEOL-40 A. Em todos esses procedimentos, as escalas foram obtidas nas mesmas condições ópticas.

\section{Resultados}

As folhas analisadas apresentam aspecto glauco, em decorrência da deposição de cera sob a forma de escamas, crostas, flocos e plaquetas (Fig. 1-5), que praticamente desaparecem após tratamento com clorofórmio (Fig. 6). Freqüentemente, observam-se hifas de fungos que podem penetrar através da abertura estomática.

As células epidérmicas, em vista frontal, dispõem-se aleatoriamente, com exceção da região correspondente à nervura central, onde ocorrem em fileiras orientadas no sentido do maior eixo da folha. Sua forma varia de retangular a elíptica ou quadrada; as paredes anticlinais são retas ou levemente curvas. Cattleya araguaiensis distingue-se das demais por apresentar estegmatas de forma elipsóide encravados nas paredes anticlinais das células epidérmicas (Fig. 7 - seta).

Em seção transversal, nota-se que a epiderme é uniestratificada (Fig. 9-11). Na face adaxial suas células são retangulares, geralmente, mais largas no sentido periclinal, excetuando a região da nervura central, em que são mais altas que largas. As paredes periclinais externas das células epidérmicas são espessadas em ambas as faces da lâmina foliar e, quase sempre, apresentam-se convexas, especialmente no bordo e sobre a nervura central. Geralmente, a superfície da cutícula não acompanha essa convexidade (Fig. 10).

A membrana cuticular, sensu Holloway, apresenta-se diversamente espessada. Em C. araguaiensis o maior espessamento da 

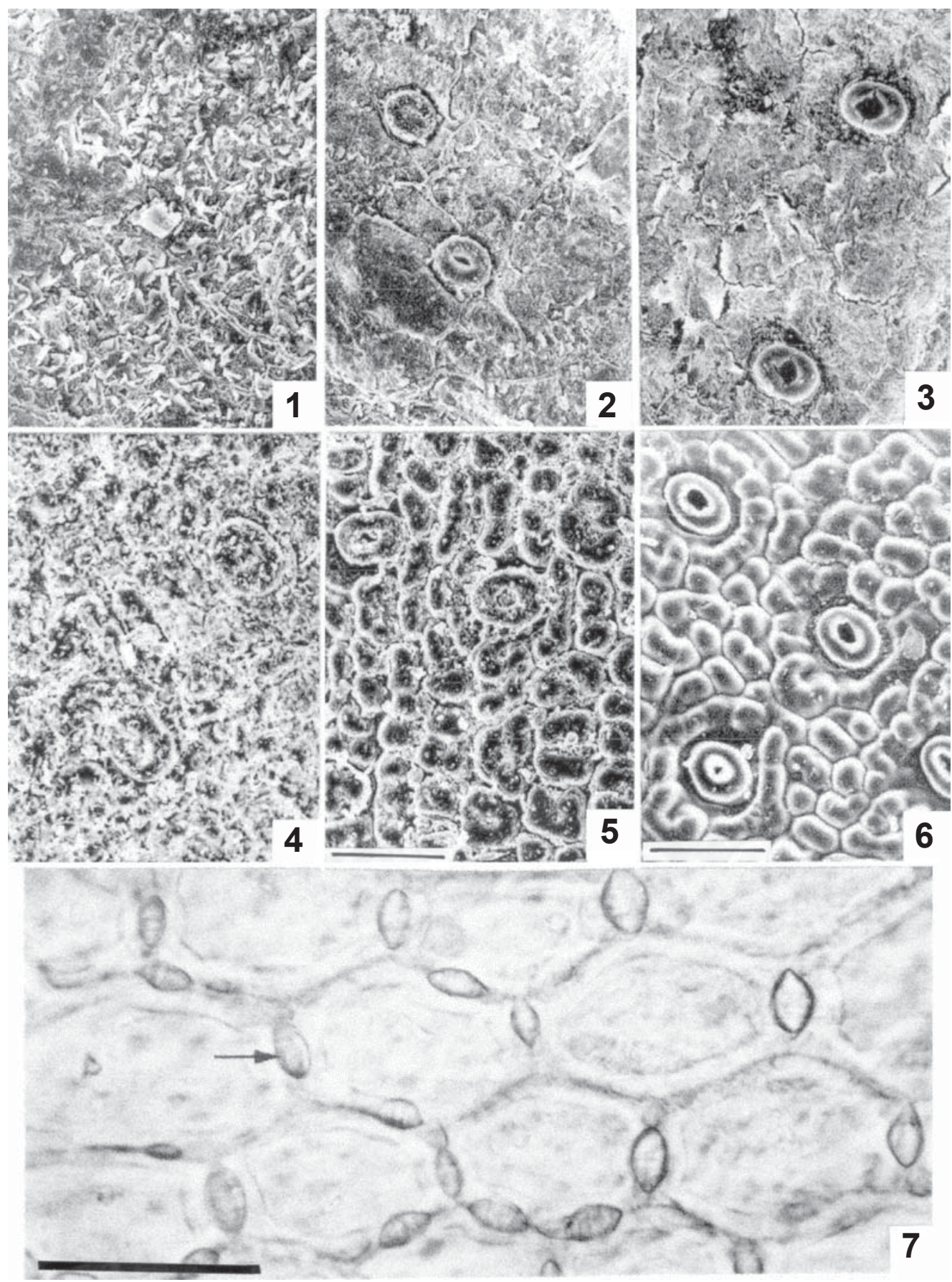

Figuras 1-7. Vista frontal da epiderme foliar. 1-5. diferentes aspectos de deposição de cera na superfície de folhas (MEV) sem tratamento: 1 e 2. Cattleya araguaiensis (ad) - escamas eretas, (ab) - escamas e crostas; 3. C. bicolor (ab) - crostas; 4: C. nobilior (ab) - escamas eretas e plaquetas; 5. C. walkeriana (ab) - escamas e flocos; 6. C. walkeriana (MEV) após tratamento com clorofórmio (ab) - nota-se a ausência de depósito de cera; observam-se estômatos ciclocíticos; 7. C. araguaiensis (MO) ad: estegmatas elipsóides (seta) encravados nas paredes anticlinais das células epidérmicas. Barra $=50 \mu \mathrm{m}$. Abreviaturas: MO (microscopia óptica); MEV (microscopia eletrônica de varredura); ad (epiderme adaxial); ab (epiderme abaxial). 
membrana cuticular ocorre na região mediana

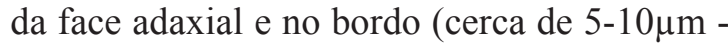
Fig. 8a). Em C. bicolor as regiões mais espessas correspondem ao bordo e à região distal da face adaxial (cerca de 10-15 $\mu \mathrm{m}$ - Fig. 8b). Cattleya nobilior e C. walkeriana apresentam espessamento igual, no bordo e em toda a extensão da face adaxial (20-25 $\mu \mathrm{m})$, assim como

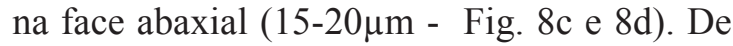
modo geral, a face adaxial é sempre mais espessa.

Testes com Sudan IV indicaram substâncias lipídicas na constituição da membrana cuticular e propiciaram melhor visualização dos flanges cuticulares. Em C. walkeriana, a membrana cuticular, sob luz polarizada, mostra regiões refringentes e outras não refringentes. O cloreto de zinco iodado evidenciou uma região mais escura na cutícula propriamente dita, que também reagiu positivamente ao vermelho de rutênio.

A superfície cuticular é lisa ou levemente ondulada, sem ornamentações, na face adaxial (Fig. 9 e 10) das quatro espécies, assim como na face abaxial de C. bicolor (Fig. 11) e C. walkeriana, revelando-se mais ondulada na face abaxial de C. nobilior.
As espécies analisadas são hipostomáticas. Os estômatos ocorrem na região intercostal da lâmina foliar, no mesmo nível das demais células epidérmicas (Fig. 11), não ocorrendo sobre a nervura mediana, em suas imediações e nos bordos. Ocorrem aleatoriamente, isolados (Fig. 2, 3, 5 e 6) ou, com menor freqüência, aos pares ou em grupos de 3-4. Foram observados os padrões anomocítico e tetracítico, predominando o tipo tetracítico em C. araguaiensis e C. bicolor. Os estômatos anomocíticos são circundados por número variável de células (4-6, freqüentemente 5). Foram registrados, também, estômatos ciclocíticos em C. nobilior e C. walkeriana (Fig. 6).

A parede periclinal externa e a membrana cuticular das células-guarda apresentam espessamento cutinizado bastante acentuado, que constitui uma crista em torno do átrio externo ao ostíolo (Fig.11 - cabeça de seta). Este aspecto é visualizado ao MEV como uma borda elevada que contorna a abertura estomática (Fig. $6 \mathrm{e}$ 12) e se apresenta mais conspícua em C. nobilior (Fig. 12 - seta preta) e C. walkeriana. Em torno das células-guarda, observa-se um sulco decorrente de reentrância na parede periclinal externa das células
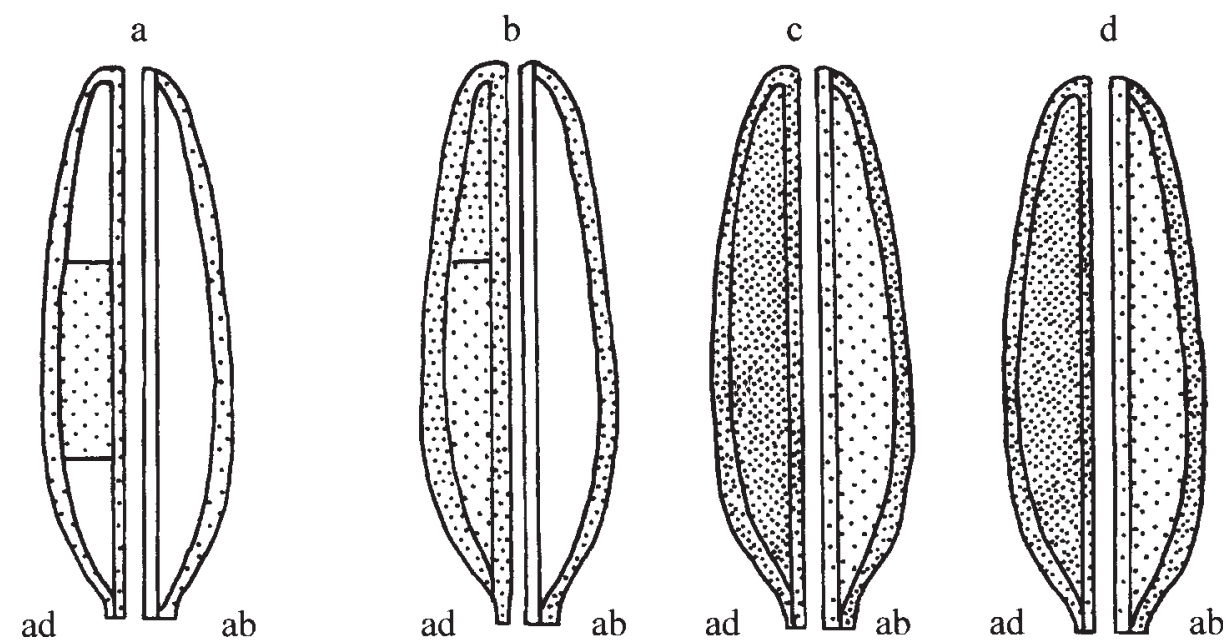

Figuras 8a-8d. Diagrama representativo da espessura aproximada, em micrômetros, da membrana cuticular. 8a. Cattleya araguaiensis; 8b. C. bicolor; 8c. C. nobilior; 8d. C. walkeriana; ad - face adaxial; ab - face abaxial. Abreviaturas: ad (face

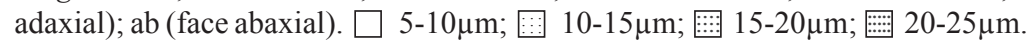



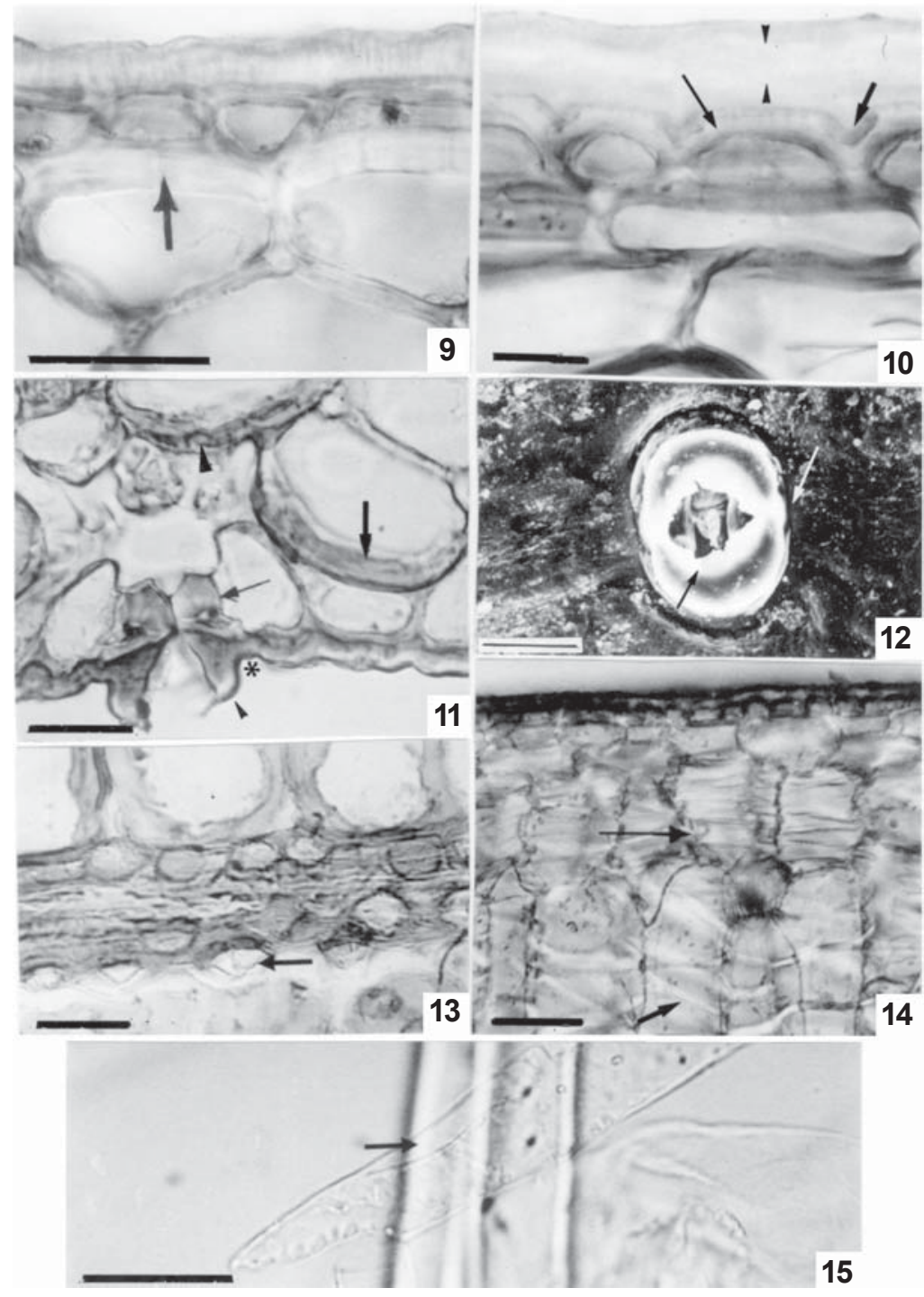

Figuras 9-15. Detalhes estruturais das folhas analisadas. 9-11 e 14. Seções transversais da lâmina foliar (MO). 9. Cattleya araguaiensis $(\mathrm{ad})$ - Nota-se espessamento acentuado na parede periclinal externa das células hipodérmicas (seta). Barra $=50 \mu \mathrm{m} ; 10$. Cattleya nobilior $(\mathrm{ad})$ - Estão assinalados: a membrana cuticular espessa, indicada pelos dois triângulos; células epidérmicas com paredes periclinais espessas (seta longa) e flanges cuticulares (seta curta); nota-se que a superfície da cutícula é lisa e não acompanha a convexidade parietal. Barra $=25 \mu \mathrm{m} ; 11$. Cattleya bicolor (ab) - São apontados: espessamento celulósico das células-guarda (seta delgada); crista cutinizada projetada sobre a abertura estomática (triângulo pequeno); parede periclinal externa espessada das células hipodérmicas (seta espessa); áreas mais delgadas, não lignificadas, na parede periclinal externa das células hipodérmicas (triângulo maior); sulco em torno das células-guarda (asterisco). Barra $=25 \mu \mathrm{m} ; 12$. Vista frontal de um estômato (MEV). C. bicolor - A borda elevada em torno da abertura estomática é indicada pela seta preta e o sulco em torno das células-guarda, pela seta branca. Barra $=$ $50 \mu \mathrm{m} ; 13$. Secção longitudinal paradérmica da lâmina foliar (MO). C. bicolor - São visíveis os estegmatas cônicos (seta) que acompanham o feixe de fibras. Barra $=25 \mu \mathrm{m} ; 14$. C. araguaiensis - São apontadas as barras de espessamento nas paredes das células hipodérmicas (seta longa) e do mesofilo (seta curta). Barra $=10 \mu \mathrm{m}$. 15. Material dissociado do xilema (MO, contraste de fase): $C$. bicolor - Assinala-se a placa de perfuração simples (seta) em uma das extremidades do elemento de vaso. Barra $=25 \mu \mathrm{m}$. Abreviaturas: MO (microscopia óptica); MEV (microscopia eletrônica de varredura); ad (epiderme/face adaxial); ab (epiderme/face abaxial). 
subsidiárias (Fig. 6 e 12 - seta branca). O lume das células-guarda, na região equatorial é pequeno e triangular, e o espessamento celulósico das paredes periclinais é mais evidente na face interna (Fig. 11). A câmara subestomática apresenta dimensões variadas.

Testes estatísticos apontam diferenças significativas na densidade média dos estômatos/ $\mathrm{mm}^{2}$ entre as espécies e entre as regiões analisadas (proximal, mediana e distal), em uma mesma espécie (Tab. 1). Em C. araguaiensis e $C$. walkeriana todas as médias diferem significativamente; em C. bicolor, as diferenças foram notadas nas regiões proximal/distal e proximal/mediana e em $C$. nobilior, nas regiões mediana/distal e proximal/distal. As médias das densidades estomáticas nas regiões medianas de cada espécie também revelam diferenças significativas (Tab. 1).

Tanto na face adaxial como na abaxial da lâmina foliar das espécies analisadas, ocorre uma hipoderme, constituída por células maiores que as epidérmicas. As paredes das células hipodérmicas são espessas e lignificadas, especialmente as periclinais externas (Fig. 9 e 11 seta). Na face abaxial, a hipoderme pode apresentar de um a três estratos celulares, cujas células possuem espessamento parietal irregular, onde se observam áreas mais delgadas, não lignificadas. Estas áreas são mais conspícuas em C. bicolor (Fig. 11 - triângulo) e C. walkeriana.
Os estratos hipodérmicos, na face abaxial, são interrompidos a espaços mais ou menos regulares, por fibras esclerenquimáticas que formam cordões paralelos, no sentido longitudinal da lâmina foliar. Cortes paradérmicos permitem verificar que essas fibras são acompanhadas por estegmatas de forma elipsóide (Fig. 13 e 26).

O mesofilo é bifacial, compacto (Fig. 18). O parênquima paliçádico (cinco ou seis estratos) é atípico, com barras de espessamento em suas células, aspecto que é mais notado em C. araguaiensis (Fig. 14 e 18). O parênquima lacunoso é constituído por um número variável de camadas celulares: de dois a quatro em C. araguaiensis (Fig. 18), cerca de seis em C. bicolor, sete a oito em C. walkeriana e, aproximadamente, dez em $C$. nobilior. As células do parênquima lacunoso têm formas diversas e, freqüentemente, são braciformes. Em todo o mesofilo ocorrem idioblastos com ráfides de oxalato de cálcio, envoltos por bainha mucilaginosa.

$\mathrm{Na}$ região da nervura mediana o parênquima clorofiliano está presente e o feixe vascular, de pequeno calibre, localiza-se próximo da epiderme abaxial (Fig. 16 e 19-22), da qual é separado por número limitado de camadas de células (duas em $C$. araguaiensis e duas a três em $C$. bicolor). As células do parênquima clorofiliano, que rodeiam o feixe vascular, geralmente, apresentam disposição radiada (Fig. 17).

Tabela 1. Comparação dos dados da densidade estomática média $\mathrm{mm}^{2}$ entre as três regiões analisadas das folhas em estudo; nível de significação de 0,05

Densidade estomática média/milímetro quadrado

Regiões estudadas

\begin{tabular}{|c|c|c|c|c|c|c|c|c|}
\hline \multirow{3}{*}{ Espécie } & \multirow{2}{*}{\multicolumn{2}{|c|}{ Proximal }} & \multirow{2}{*}{\multicolumn{2}{|c|}{ Mediana }} & & & \multirow{2}{*}{\multicolumn{2}{|c|}{ Total }} \\
\hline & & & & & \multicolumn{2}{|c|}{ Distal } & & \\
\hline & $\mathrm{M}$ & $\overline{\mathrm{DP}}$ & $\mathrm{M}$ & $\overline{\mathrm{DP}}$ & $\mathrm{M}$ & $\mathrm{DP}$ & $\mathrm{MM}$ & MDP \\
\hline C. araguaiensis & 29,78 & 6,04 & 54,64 & 6,41 & 50,84 & 5,74 & 45,09 & 6,06 \\
\hline C. bicolor & 22,80 & 3,79 & 20,84 & 3,90 & 19,38 & 8,00 & 21,01 & 5,23 \\
\hline C. nobilior & 66,96 & 14,03 & 69,15 & 10,28 & 46,88 & 8,72 & 61,01 & 11,02 \\
\hline C. walkeriana & 36,00 & 8,29 & 40,16 & 8,10 & 40,44 & 8,73 & 38,87 & 8,37 \\
\hline
\end{tabular}

$\mathrm{M}=$ média; $\mathrm{DP}=$ desvio padrão $\mathrm{MM}=$ média da média MDP = média de DP 

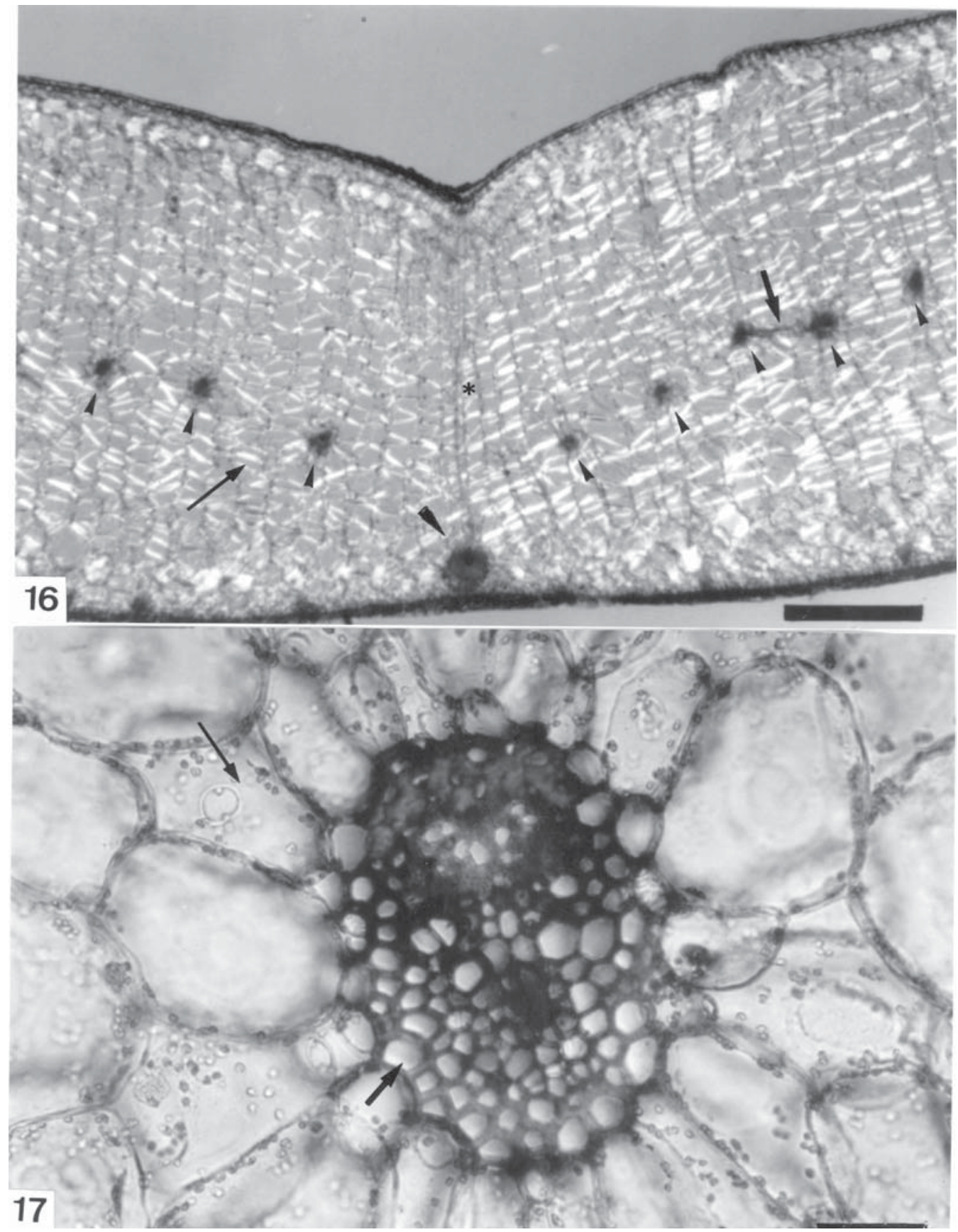

Figuras 16-17. Apectos estruturais da lâmina foliar em seção transversal (MO e LP). 16. Cattleya araguaiensis (LP) Notam-se as barras de espessamento nas células hipodérmicas e clorenquimáticas (seta delgada); o arranjo dos feixes vasculares (triângulos pequenos); feixe vascular da nervura mediana localizada nas proximidades da epiderme abaxial (triângulo maior); uma nervura comissural (seta espessa); células clorenquimáticas alongadas na região da nervura central (asterisco). Barra $=350 \mu \mathrm{m}$. 17. C. bicolor $(\mathrm{MO})$ - Detalhe do feixe vascular da nervura central, observa-se a disposição radiada das células clorenquimáticas que rodeiam o feixe vascular (seta delgada); fibras acompanham os elementos de xilema e de floema (seta espessa). Barra $=100 \mu \mathrm{m}$. Abreviaturas: MO (microscopia óptica); LP (luz polarizada). 


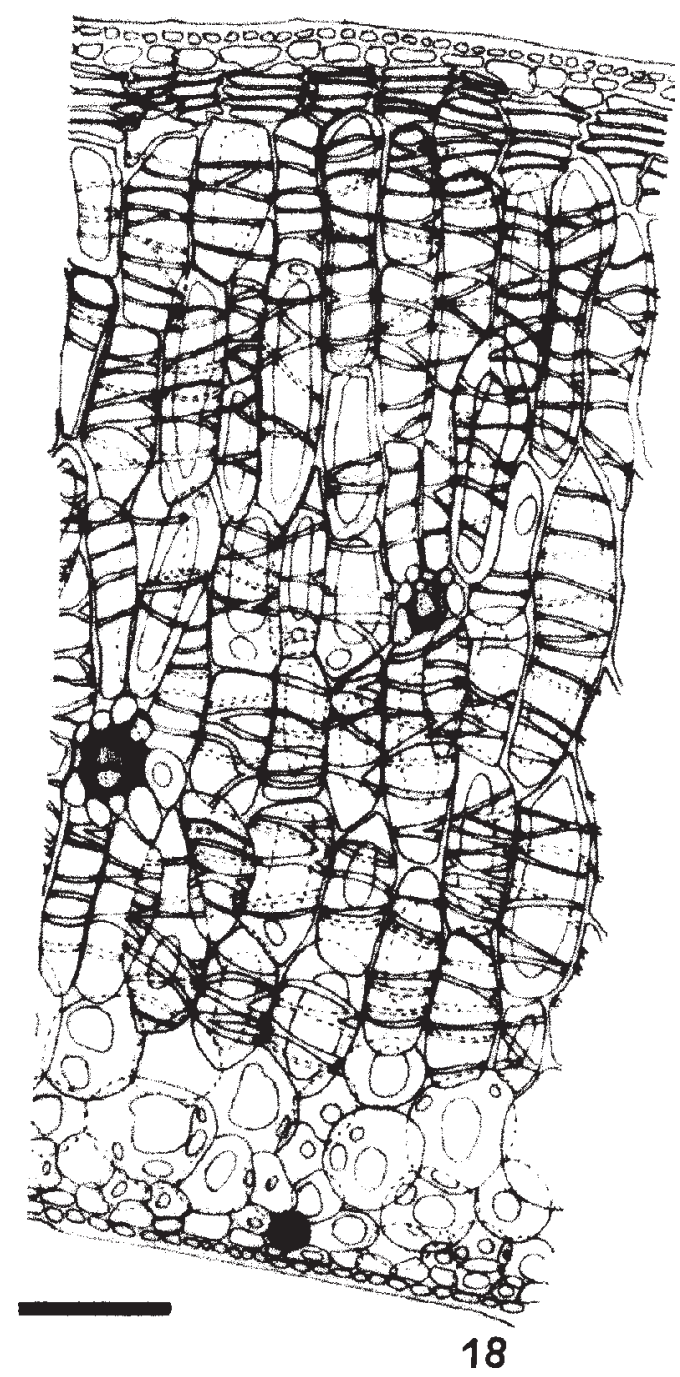

Figura 18. Cattleya araguaiensis - Ilustração representativa da seção transversal da lâmina foliar, terço médio da região intercostal, evidenciando o mesofilo compacto, com o parênquima paliçádico em cerca de seis estratos e o lacunoso, em até quatro; barras de espessamento nas células hipodérmicas e clorenquimáticas (seta). Barra $=250 \mu \mathrm{m}$.

Em $C$. araguaiensis, estas células se dispõem no sentido anticlinal, e apresentam as barras de espessamento características. Em C. bicolor, as células da camada subepidérmica, na face adaxial, são alongadas no sentido anticlinal e dispostas em leque e, em C. nobilior, os idioblastos com ráfides são freqüentes. Nesta região não ocorrem os cordões de fibras.
Nas quatro espécies o bordo foliar apresenta-se fletido em direção à face abaxial. Nessa região as células epidérmicas são menores, com flanges evidentes nas paredes periclinais externas, que são convexas. A membrana cuticular e a cutícula propriamente dita não acompanham essa convexidade. Neste nível, as células hipodérmicas são substituídas por células clorenquimáticas, de formato mais regular. Ocorrem idioblastos com ráfides e um maciço de fibras.

Os feixes vasculares dispõem-se paralelamente em relação ao eixo longitudinal da lâmina foliar (Fig. 16 e 19-22), caracterizando o padrão de venação paralelódromo; são freqüentes nervuras comissurais (Fig. 16 e 24). O número de feixes é maior na região mediana da lâmina foliar e só os feixes de maior calibre atingem o nível distal da lâmina. Os feixes de maior e de médio porte são acompanhados por uma bainha ou por uma calota de fibras esclerenquimáticas (Fig. 17). Em seções transversais, verifica-se que os feixes de maior e de menor porte estão localizados em alturas diferentes na lâmina foliar (Fig. 19a-22d). Esta situação é melhor evidenciada em C. bicolor (Fig. 20a-20d).

A bainha fibrosa que envolve os feixes vasculares é mais espessa na região da bainha foliar e na base da lâmina (Fig. 23). Nestas regiões as anastomoses entre os feixes são mais freqüentes (Fig. 24) e os cordões de fibras são abundantes (Fig. 23).

Os elementos condutores do xilema estão representados por traqueídes de vários tamanhos, cujas paredes apresentam espessamento espiralado ou espiralado tendendo a reticulado (Fig. 27). Algumas vezes, os espessamentos não formam espiral contínua e se restringem às extremidades do elemento condutor. Em C. bicolor observa-se uma placa de perfuração simples, em uma das extremidades de alguns elementos de vaso (Fig. 15). O tecido de sustentação é representado por fibras libriformes e fibro-traqueídes, cujas paredes, freqüentemente, são polilamelares (Fig. 25). 


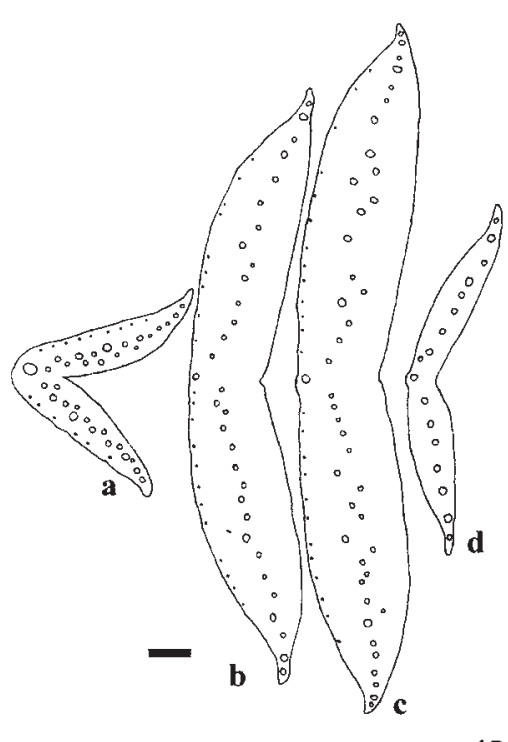

19

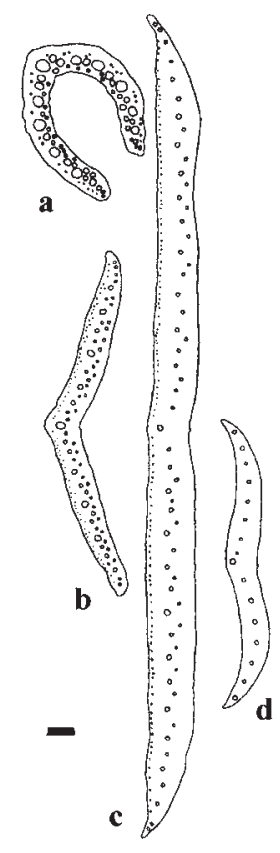

20

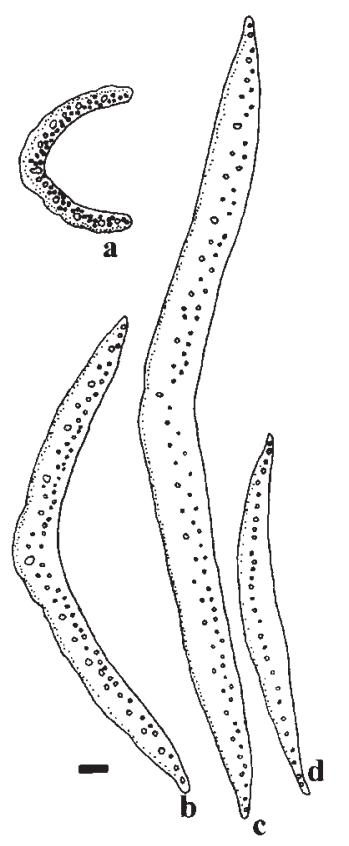

21

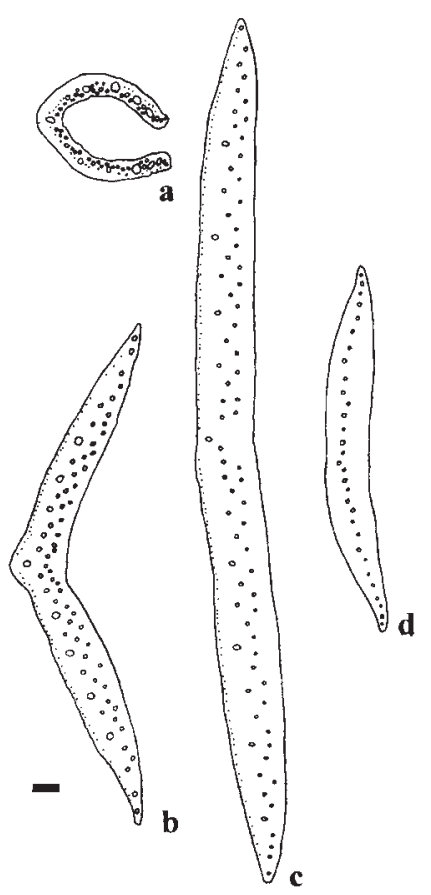

22

Figuras 19-22. Diagramas da bainha e da lâmina foliar em seção transversal, nas regiões proximal, mediana e distal, evidenciando a disposição dos dos feixes vasculares e dos cordões de fibras. 18. Cattleya araguaiensis - a) bainha; b) lâmina foliar, base; c) terço médio; d) ápice; 19. C. bicolor - a) bainha; b) lâmina foliar, base; c) terço médio; d) ápice. 20. C. nobilior - a) bainha; b) lâmina foliar, base; c) terço médio; d) ápice.21: C. walkeriana - a) bainha; b) base; c) terço médio; d) ápice. Barra $=1 \mathrm{~mm}$. 

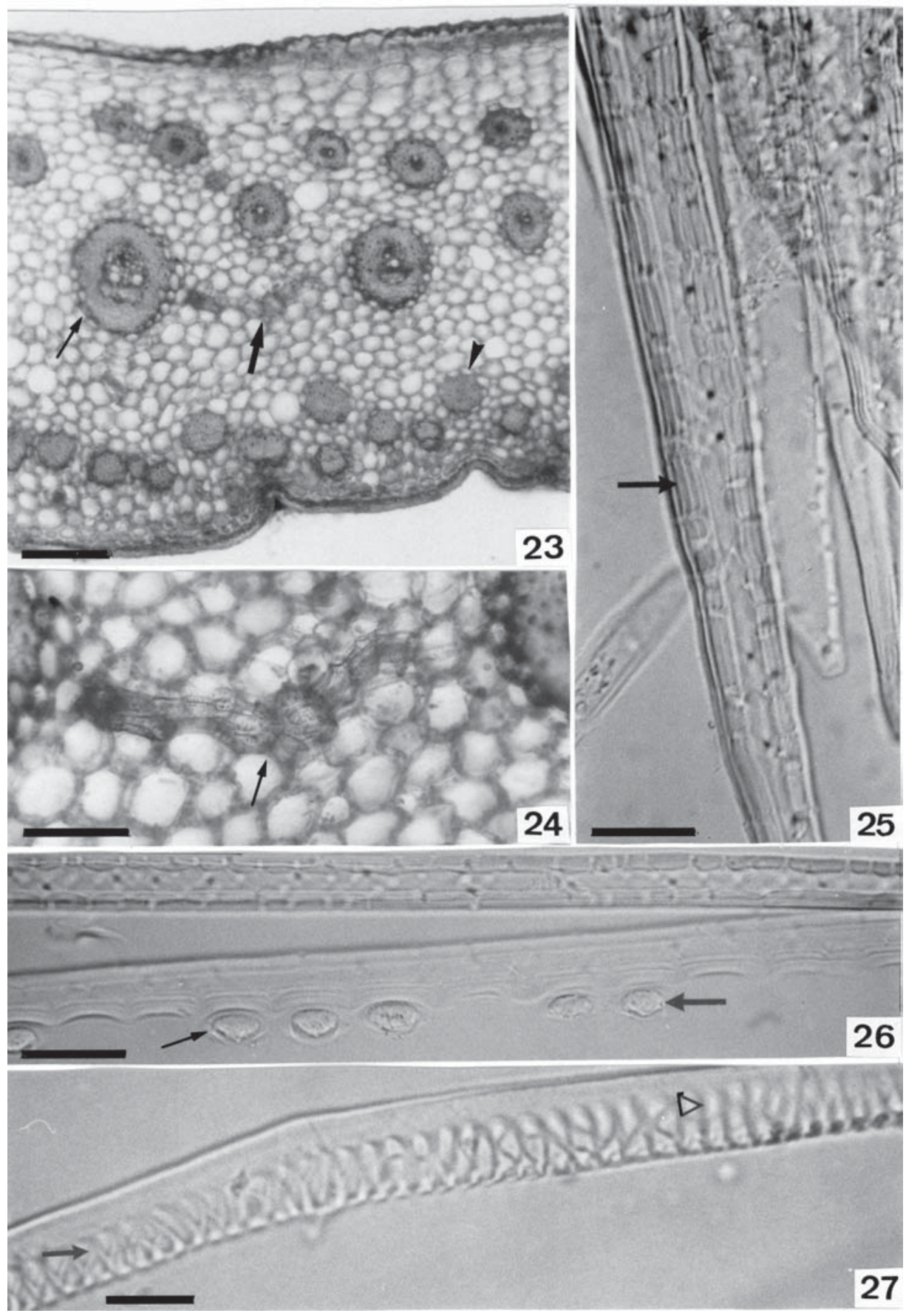

Figuras 23-27. Detalhes estruturais da lâmina foliar. 23-24. seção transversal na região basal e na mediana (MO); 23. Cattleya bicolor (rb) - Estão assinalados: bainha fibrosa espessa em torno do feixe vascular (seta delgada); anastomose entre dois feixes vasculares (seta espessa); numerosos cordões fibrosos. Barra $=200 \mu \mathrm{m} ; 24$. C. nobilior - Anastomose entre dois feixes vasculares (seta). Barra $=50 \mu \mathrm{m}$. 25-27. Material dissociado (CF); 25. C. nobilior - Fibra com paredes polilamelares (seta). Barra $=50 \mu \mathrm{m}$ C. araguaiensis - Fibra acompanhada por corpos silicosos de forma elipsóide (seta). Barra $=50 \mu \mathrm{m} ; 2$. C.bicolor - Traqueíde com espessamento parietal espiralado (seta) que, em alguns trechos, tende a reticulado (triângulo). Barra $=25 \mu \mathrm{m}$. Abreviaturas: $\mathrm{MO}$ (microscopia óptica); $\mathrm{CF}$ (contraste de fase); (rb) região da base. 


\section{Discussão}

A conquista do hábito epifítico pelas plantas passa por etapas desfavoráveis, das quais a mais drástica é o estresse hídrico. Segundo Dressler (1990), as condições de epifitismo equivalem, em muitos aspectos, às das regiões desérticas. Walter (1986 apud Campos Leite \& Oliveira 1987) considera a luz como um dos fatores climáticos mais relevantes para os vegetais epífitos e acredita que o epifitismo surgiu em função da busca de condições mais favoráveis de luz. Oliveira (1997) assinala que $80 \%$ de todas as espécies epífitas estão distribuídas em apenas quatro famílias - Bromeliaceae, Orchidaceae, Polypodiaceae e Araceae, o que demonstra que poucas famílias participaram efetivamente desse evento. Johansson (1975) refere que o padrão de distribuição das orquídeas parece resultar, primordialmente, da necessidade de altas intensidades luminosas e que a composição do substrato, quase sempre, é de importância secundária. Dressler (1990) assinala que algumas orquídeas, assim como outras epífitas, desenvolvem-se em florestas sombrias ou em terrenos arenosos, habitats em que as plantas terrestres medram com dificuldade, face à deficiência de nutrientes. Três das espécies epífitas aqui analisadas são provenientes de mata sombreada (C. araguaiensis, C. bicolor e C. walkeriana, que também se desenvolve sobre rochas) e a quarta, C. nobilior, é procedente de mata decídua.

As epífitas, geralmente, desenvolvem estratégias para reserva de água em órgãos suculentos, quer sejam raízes, caules ou folhas. Entre as estruturas envolvidas nesse processo, a hipoderme é uma das mais citadas (Scatena \& Menezes 1996). A hipoderme é, comumente, referida em espécies epífitas de famílias diversas de mono e dicotiledôneas (Oliveira \& Sajo 1999) e, de modo particular, em espécies de Orchidaceae (Khasim \& Mohana-Rao 1990; Oliveira \& Sajo 1999). Esta estrutura, que também desempenha função de sustentação
(Kraus 1949; Costa 1989), é considerada adaptativa ao ambiente e utilizada como elemento adicional para classificar distintos grupos dentro do gênero Oncidium (Williams 1972). Embora sem o amparo de estudos ontogenéticos, as camadas subepidérmicas observadas nas espécies analisadas estão sendo consideradas como hipoderme, face às suas peculiaridades estruturais e ao respaldo bibliográfico.

Observações ao MEV evidenciaram a presença de cera epicuticular nas folhas em estudo, podendo ocorrer mais de um padrão na mesma folha, o que vem ao encontro das observações de Machado \& Barros (1995) e Barthlott et al. (1998). Machado \& Barros (1995) mencionam que, em uma mesma espécie, podem ser observadas variações nos tipos de cera, o que não foi detectado no material em estudo. Salatino et al. (1986) assinalam que os cristais de cera, assim como as estrias epicuticulares e os tricomas, podem ser importantes fatores de adaptação às condições ambientais do cerrado, onde predominam altas intensidades luminosas e elevadas taxas de transpiração. Barros (1998) assinala que a configuração, o tamanho e a distribuição dos depósitos de cera podem ser de interesse taxonômico. Baker (1982), por sua vez, refere que esses aspectos, apesar de controlados geneticamente, podem ser modificados de acordo com as condições ambientais. Antes de inferir qualquer utilização taxonômica dos padrões de cera visualizados no material em estudo, faz-se necessário observar maior número de amostras. Acredita-se, entretanto, que as condições ambientais do cerrado influenciem a ocorrência de cera epicuticular nessas folhas.

No material analisado, observa-se, com freqüência, a penetração de hifas de fungos através dos estômatos, principalmente em C. araguaiensis. Martin (1964) relata a entrada de alguns fungos por aberturas naturais na cutícula, como estômatos ou ferimentos, 
enquanto outros o fazem, ao que parece, diretamente através da membrana cuticular, o que não foi detectado nas espécies estudadas.

Holloway (1982) conceitua a cutícula propriamente dita (camada extracelular), juntamente com os estratos cuticulares, como membrana cuticular, conotação adotada neste trabalho. Morris et al. (1996), estudando espécies de Orchidaceae da subtribo Dendrobiinae, propuseram três categorias de espessura da cutícula: $<3 \mu \mathrm{m}=$ finas, $3-10 \mu \mathrm{m}=$ moderadamente espessas e $>10 \mu \mathrm{m}=$ espessas, classificação também utilizada por Stern et al. (1993b). Comparando essas categorias com os dados obtidos, pode-se concluir que as espécies em estudo possuem cutícula espessa $(>10 \mu \mathrm{m})$, sendo que $C$. araguaiensis e $C$. bicolor também apresentam áreas que podem ser consideradas moderadamente espessas. Em todas as espécies estudadas, especialmente C. nobilior e C. walkeriana, os estratos cuticulares são mais espessos na face adaxial. Esta característica foi relatada anteriormente para outras espécies da família por Campos Leite \& Oliveira (1987), Ferreira (1992) e Leiria (1997). Segundo os autores, este aspecto reflete o controle genético (Wilkinson 1988) da planta, bem como as suas necessidades em relação ao ambiente (Haberlandt 1965).

As folhas das espécies estudadas são hipoestomáticas, confirmando as referências sobre o gênero Cattleya (Campos Leite \& Oliveira 1987; Bonates 1993) e outros da família. Quanto aos padrões estomáticos das espécies em pauta foram descritos os tipos tetracítico, anomocítico e ciclocítico, o que vem ao encontro dos resultados obtidos para Sophronitis por Widholzer (1993). Os estômatos das xerófitas localizam-se freqüentemente em depressões ou estão rodeados por projeções cuticulares ou bastonetes de cera que, de algum modo, os protegem contra a perda excessiva de água e gases (Eames \& MacDaniels 1925, Metcalfe 1963; Machado \& Barros 1995). Projeções cuticulares sobre as células-guarda constituem outra característica desses estômatos e têm sido mencionadas para espécies de orquídeas (Ferreira 1992; Leiria 1997). Singh (1974) menciona vários padrões de desenvolvimento estomático nas orquidáceas, que produzem diferentes tipos de estômatos até em uma mesma folha. Rasmussen (1981a) apontou a existência de células subsidiárias em orquídeas e salientou que durante o desenvolvimento, ocorrem alterações nas características estomáticas que podem induzir a erros de interpretação, quando as folhas são analisadas na maturidade. $\mathrm{Na}$ classificação dos padrões estomáticos das espécies em análise, assim como na referência às células subsidiárias, levou-se em consideração apenas o aspecto topográfico, sem qualquer conotação ontogenética.

Jones (1996) refere que a freqüência e o tamanho dos estômatos variam com a posição da folha e as condições de crescimento e que em uma mesma espécie pode ocorrer um componente genético de variação, entre cultivares ou ecótipos. Campos Leite \& Oliveira (1987), estudando $C$. intermedia, obtiveram diferenças significativas entre as médias das densidades estomáticas $/ \mathrm{mm}^{2}$ de folhas de sol e sombra. Wilkinson (1988) assinalou altas densidades estomáticas para plantas xerófitas, a exemplo de Miconia pycnoneura, em que ele registrou 2230 estômatos $/ \mathrm{mm}^{2}$ como maior valor encontrado, mas ressalva que nem todas as plantas xerófitas apresentam densidades estomáticas tão altas. Nas espécies de Cattleya a densidade estomática média $/ \mathrm{mm}^{2}$ variou significativamente, dependendo da região da folha analisada. Lleras (1977) afirma que quanto mais xerofíticas as condições, maior a freqüência estomática por unidade de área, o que permite troca de gases mais eficiente nos períodos em que a umidade relativa é alta, quando o perigo de desidratação excessiva é mínimo. Isto poderia explicar a baixa densidade estomática de C. bicolor que se desenvolve em mata alagada durante todo o ano.

Moller \& Rassmussen (1984) apontam dois 
tipos de incrustação de sílica nos vários órgãos das orquídeas: corpos cônicos de base achatada e corpos esféricos com superfície espinhosa e acrescentam que a presença e a forma dessas incrustações são geneticamente determinadas, pouco influenciadas pelos fatores ambientais. Mauseth (1988) denomina os corpos silicosos das Orchidaceae de estegmatas, termo adotado neste trabalho. Segundo Metcalfe (1988b), entre as monocotiledôneas, os corpos silicosos freqüentemente assumem formas diferentes, que caracterizam um gênero ou espécie e algumas vezes a família na qual ocorrem. Quanto à função, Campos \& Labouriau (1969) mencionam que a presença de sílica na epiderme de gramíneas dos cerrados está relacionada às trocas hídricas com a atmosfera, ao balanço de trocas térmicas e à refletância das folhas. Paviani (1972) associa a ocorrência de sílica na epiderme das folhas de Brasilia sickii, espécie endêmica no Distrito Federal e Goiás, à redução da transpiração, retenção de água e à defesa contra microrganismos. Metcalfe (1988b) assinala que os corpos silicosos na superfície da epiderme previnem o colapso dos tecidos subjacentes, servindo como um envelope protetor rígido contra a perda de água. Nas espécies de Cattleya analisadas, ocorrem estegmatas cônicos junto às fibras e outros com formato elipsóide na epiderme de $C$. araguaiensis, o que constitui caráter distintivo para a espécie que, dentre as quatro, apresenta características xeromórficas mais acentuadas. Esses fatos levam a crer que, nesta espécie, os estegmatas epidérmicos atuariam como coadjuvantes na redução da transpiração e na retenção de água e, por outro lado, tornariam a planta menos palatável à herbivoria. Quanto aos estegmatas que ocorrem junto aos cordões fibrosos, acreditase que possam auxiliar na sustentação do órgão foliar, função não citada na bibliografia consultada.

Segundo Esau (1965), o aumento, em proporção, do tecido paliçádico ocorre tanto em monocotiledôneas quanto em dicotiledôneas e está relacionado ao ambiente. Cattleya araguaiensis destaca-se, entre as espécies estudadas, por seu mesofilo, constituído quase exclusivamente por células paliçádicas com barras de espessamento nas paredes anticlinais. Outros trabalhos de anatomia foliar de orquídeas registram nomes diferentes para estruturas semelhantes: células traqueoidais (Olatungi \& Nengin 1980; Widholzer (1993); idioblastos espessados de forma espiralada (Pridgeon 1982); idioblastos de paredes espessadas (Ferreira 1992) e idioblastos com espessamento helicoidal (Scatena \& Nunes 1996). Para alguns autores esses espessamentos são essencialmente celulósicos (Pridgeon 1982) enquanto para outros, são lignificados. No material examinado, sua composição é basicamente celulósica, com traços de lignina. Estas células são consideradas armazenadoras de água pela maioria dos autores. Widholzer (1993) salienta que elas desempenhariam não somente essa função, como representariam também uma estratégia contra o dessecamento contribuindo, desta maneira, para manter a forma da folha. Acredita-se que, no material em estudo, as barras de espessamento desempenhem as duas funções.

As espécies estudadas têm mesofilo compacto, parênquima lacunoso com poucos estratos celulares e, conseqüentemente, volume reduzido de espaços intercelulares. Estes aspectos, segundo Eames \& McDaniels (1925) e Esau (1977) constituem características xeromorfas e refletem condições ambientais xerofíticas. James et al. (1999) mencionam que nem sempre o desempenho fotossintetizante é maior nas células paliçádicas, e que a compactação do mesofilo pode indicar um reforço estrutural. Segundo estes autores, em virtude desse reforço mecânico, quando o volume de parênquima esponjoso é mais baixo em relação ao volume de parênquima paliçádico, a forma das folhas é menos impactada pela desidratação. Diante do exposto, depreende-se que as características observadas nas folhas analisadas, de modo especial em 
C. araguaiensis, além de refletir as influências ambientais, teriam papel coadjuvante quanto à manutenção da forma da folha.

Em todas as espécies analisadas, de modo particular em C. nobilior, ocorrem idioblastos com ráfides de oxalato de cálcio, o que vem a corroborar as referências sobre a família (Metcalfe 1963; Wattendorff 1976; Franceschi \& Horner 1980; Kauschik 1982; Pridgeon 1982; Campos Leite \& Oliveira 1987; Ferreira 1992; Widholzer 1993; Leiria 1997). Mauseth (1995) acredita que o oxalato de cálcio contribui para tornar as plantas menos palatáveis aos animais, frisando, no entanto, que a função do oxalato na biologia vegetal é questão ainda controversa.

Um dos caracteres constantes entre as monocotiledôneas é a grande proporção de fibras (Cutter 1986; Fahn 1990). Segundo Eames \& MacDaniels (1925), as fibras desempenham diferentes funções: sustentação, proteção contra a perda de água e filtração da intensidade luminosa. Acredita-se que todas essas funções sejam desempenhadas pelas fibras ocorrentes no material em estudo.

Stebbins \& Khush (1961) consideram o grupo das orquídeas tropicais epífitas como o mais especializado da família, sob o aspecto filogenético. A distribuição diversificada do espessamento parietal nas traqueídes e a ocorrência de fibrotraqueídes (assim considerados segundo conceito da IAWA 1989), sugerem que as espécies em estudo encontram-se numa fase avançada de desenvolvimento filogenético. Por outro lado, a presença, em C. bicolor, de elementos condutores com placa de perfuração simples em uma das extremidades, leva a supor que esta espécie atingiu um estádio de desenvolvimento evolutivo relativamente avançado em relação às demais. Esta suposição é apoiada pelas considerações de Metcalfe (1963), segundo o qual, entre as monocotiledôneas mais evoluídas, os elementos condutores são constituídos de vasos.
As observações aqui desenvolvidas sugerem que as características acentuadamente xeromorfas das espécies de Cattleya refletem estratégias destinadas à economia de água. $\mathrm{O}$ desenvolvimento dessas estratégias resulta, fundamentalmente, do hábito epifítico dessas plantas, que pode conduzir a uma situação de seca, mesmo em plantas que se desenvolvem em ambiente em que não há deficiência de água. Tendo em vista que as características anatômicas das espécies analisadas são próprias da família e do gênero, conseqüentemente, não podem ser utilizadas para fins taxonômicos. Entretanto, no caso particular de C. araguaiensis alguns desses aspectos - estegmatas epidérmicos, mesofilo mais compacto e maior proporção de barras de espessamento nas células paliçádicas - podem ser usados com essa finalidade.

\section{Agradecimentos}

Ao Chefe do Departamento de Botânica do Instituto de Biologia da Universidade de Brasília, onde este trabalho foi desenvolvido; À Profa. Dra. Maria Elisa Calbo, Chefe do Departamento - $\mathrm{CNPq}$, pela bolsa concedida à segunda autora.

\section{Referências bibliográficas}

Arditti, J. 1992. Fundamentals of orchid biology. John Wiley. New York.

Amaral, M. C. E.; Salatino, M. L. F. \& Salatino, A. 1985. Teor de cera foliar epicuticular de dicotiledôneas do cerrado. Revista Brasileira de Botânica 8:127-130.

Baker, E. A. 1982. Chemistry and morphology of plant epicuticular waxes. In: D. F. Cutler; K. L. Alvin \& C. E. Price (eds.) The Plant Cuticles. Linnean Society Symposium Series: 10, Academic Press, London.

Barthlott, W.; Neinhuis, C.; Cutler, D.; Ditsch, F.; Mensel, I; Theisen, I. \& Wilhelm, H. 1998. Classification and terminology of plant epicuticular waxes. Botanical Journal of the Linnean Society 126: 237-260.

Barros, C. F. 1998. Estudo da epiderme foliar de espécies tropicais. Tese de Doutorado. Universidade Federal do Rio de Janeiro, Rio de Janeiro. 
Bechtel, H.; Cribb, P. \& Launert, E. 1992. The manual of cultivated orchid species. 3 th. ed.. The Mit Press, Cambridge.

Benzing, D. H.; Ott, D. W. \& Friedman, W. E. 1982. Roots of Sobralia macrantha (Orchidaceae): structure and function of the velamen-exodermis complex. American Journal of Botany 69: 508-614.

Bonates, L. C. M. 1993. Estudos ecofisiológicos de Orchidaceae da Amazônia II - Anatomia ecológica foliar de espécies com metabolismo CAM de uma campina da Amazônia Central. Acta Amazonica 23(4): 315-348.

Campos, A. C. \& Labouriau, L. G. 1969. Corpos silicosos de gramíneas dos cerrados. II. Pesquisa Agropecuária Brasileira 4: 143-151.

Campos Leite, V. M. \& Oliveira, P. L. 1987. Morfoanatomia foliar de Cattleya intermedia (Orchidaceae). Napaea 2: 1-10.

Cheadle, V. I. \& Uhl, N. W. 1948. Types of vascular bundles in the Monocotyledoneae and their relation to the late metaxylem conducting elements. American Journal of Botany 35: 486-496.

Costa, C. G. 1989. Morfologia e anatomia dos órgãos vegetativos em desenvolvimento de Marcgravia polyantha Delp. (Macgraviaceae). Tese de Doutorado. Universidade de São Paulo, São Paulo.

Cronquist, A. 1981. An integrated system of classification of flowering plants. Columbia University Press, New York.

Cutter, E. G. 1986. Anatomia vegetal Parte II. Órgãos - Experimentos e interpretação. Livraria Roca Ltda. $1^{a}$ ed., São Paulo.

Dressler, R.L. 1990. The Orchids: natural history and classification. Harvard University Press, Cambridge

Eames, A. J. \& MacDaniels, L. H. 1925. An introduction to plant anatomy. McGraw-Hill Book Company, Inc, New York.

Esau, K. Plant anatomy. 1965. 2nd. ed. John Wiley \& Sons, New York.

Esau, K. 1977. Anatomy of seed plants. $2^{\text {nd }}$. ed. John Wiley \& Sons, New York.

Fahn, A. 1990. Plant anatomy. $4^{\text {th }}$ ed. BlutterworthHeinemann Ltd., Oxford.

Ferreira, J. L. B. 1992. Anatomia foliar de espécies da subtribo Pleurothallidinae (Orchidaceae). Dissertação de Mestrado. Universidade Federal do Rio Grande do Sul, Porto Alegre.

Filgueiras, T. S. \& Pereira, B. A. S. 1990. Flora do Distrito Federal. In: M. N. Pinto (Org.) Cerrado Caracterização, Ocupação e Perspectivas. Editora UnB, Brasília.
Franceschi, V. R. \& Horner Jr., H. T. 1980. Calcium oxalate crystals in plants. The Botanical Review 46: 361-427.

Gunning, B. E. S. \& Steer, M. W. 1985. Ultrastructure and the biology of plant cells. Edward Arnold, London.

Haberlandt, G. 1965. Physiological plant anatomy. Today \& Tomorrow's Book Agency, New Delhi.

Holloway, P. J. 1982. Structure and histochemistry of plant cuticular membranes: an overview. In: D. F. Cutler, K. L. Alvin \& C. E. Price (eds.). The Plant Cuticle. Academic Press, London.

IAWA List of microscopic features for hardwood identification. 1989. IAWA Bulletin. 10(3): 219-332.

James, S. A.; Smith, W. K. \& Vogelmann, T. C. 1999. Ontogenetic differences in mesophyll structure and achlorophyll distribution in Eucalyptus globules ssp. globules (Myrtaceae). American Journal of Botany 86: $198-215$.

Johansson, D. A. 1940. Plant microtechnique. McGraw-Hill, New York.

Johansson, D. J. 1975. Ecology of epiphytic orchids in west African rain forests. American Orchid Society Bulletin - February: 125-136.

Jones, H. G. 1996. Plants and microclimate. A quantitative approach to environmental plant physiology. $2^{\text {nd }}$ ed. Cambridge University Press, New York.

Kauschik, P. 1982. Anatomy of Aerides (Orchidaceae) and its ecological and taxonomical bearing. Phytomorphology 40: 157-166.

Khassim, J. E. \& Mohana-Rao. 1990. Anatomy in relation to taxonomy in some members of Epidendroideae (Orchidaceae). Phytomorphology 40: $243-250$.

Kraus, B. H. 1949. Anatomy of vegetative organs of the pineapple Ananas comosus (L.) Merr. II. The leaf. Botanical Gazete. 110(3): 303-404.

Kraus, J. E. \& Arduin, M. 1997. Manual básico de métodos em morfologia vegetal. EDUR (Editora Universidade Rural), Rio de Janeiro.

Leiria, D. P. S. 1997. Anatomia foliar das espécies nativas do gênero Oncidium Sw., Seção Synsepala (Orchidaceae) ocorrentes no morro Santana (POA) - RS. Dissertação de Mestrado. Universidade Federal do Rio Grande do Sul, Porto Alegre.

Lleras, E. 1977. Differences in stomatal number per unit area within the same species under different micro-environmental conditions: a working hypothesis. Acta Amazonica 7(4): 473-476. 
Lyshede, O. B. 1982. Structure of outer epidermal walls in xerophytes. In: D. F. Cutler; K. L. Alvin \& C. E. Price (eds.). The Plant Cuticle. Academic Press, London.

Machado, R. D. \& Barros, C. F. 1995. Epidermis and epicuticular waxes of Syagrus coronata leaflets. Canadian Journal of Botany 73: 1947-1952.

Madison, M. 1977. Vascular epiphytes: their systematic occurrence and salient features. Selbyana 2: 1-13.

Martin, J. T. 1964. Role of cuticle in the defense against plant disease. Annual Review of Phytopathology 2: $81-100$.

Martin, J. T. \& Juniper, B. E. 1970. The cuticles of plants. Edward Arnold (Publishers) Ltd, Edinburgh.

Mauseth, J. D. 1988. Plant anatomy. The Benjamin Cummings Publishing Company, Inc. California.

Mauseth, J. D.1995. Botany-An introduction to Plant Biology. $2^{\text {nd }}$ ed., Sanders College Publishing, Menlo Park.

Metcalfe, C. R. 1979. Comparative anatomy as a modern botanical discipline. Advances in Botanical Research 1: 101-147.

Metcalfe, C. R. 1979. The Leaf: general topography and ontogeny of the tissues. In: Metcalfe, C. R. \& Chalk, L. Anatomy of the Dicotyledons. Systematic anatomy of the leaf and stem, with a brief history of the subject. $2^{\text {nd }}$ ed. vol I.Clarendon Press, Oxford.

Metcalfe, C. R. 1983. Ecological anatomy and morphology. General survey. In: Metcalfe, C. R. \& Chalk, L. Anatomy of the dicotyledons. Wood structure and conclusion of the general introduction. $2^{\text {nd }}$ ed. vol II .Clarendon Press, Oxford.

Moller, J. D. \& Rasmussen, F. L. S. 1984. Stegmata in Orchidales: character state distribution and polarity. Botanical Journal of the Linnean Society 89: 53-76.

Morris, M. W.; Stern, W. L. \& Judd, W. S. 1996. Vegetative anatomy and systematic of subtribe Dendrobiinae (Orchidaceae). Botanical Journal of the Linnean Society 120: 89-114.

Norris, R. F. \& Bukovac, M. J. 1968. Structure of the leaf cuticle with special reference to cuticular penetration. American Journal of Botany 55(8): 975-983.

Olatunji, O. A. \& Nengim, R. O. 1980. Ocurrence and distribution of tracheoidal elements in the Orchidaceae. Botanical Journal of the Linnean Society 80: 357-370.
Oliveira. A. M. 1997. Considerações iniciais sobre a conquista do hábito epifítico na família Araceae. Dissertação de Mestrado. Universidade Federal do Rio de Janeiro, Rio de Janeiro.

Oliveira, V. del C. \& Sajo, M. G. 1999. Anatomia foliar de espécies epífitas de Orchidaceae. Revista Brasileira de Botânica 22(3): 365-374.

Pabst, G. F. J. \& Dungs, F. 1975. Orchidaceae Brasiliensis. Band I Brücke-Verlag Kurt Schmersow, Hildesheim.

Parkhurst, D. F. 1978. The adaptative significance of stomatal occurrence on one or both surfaces of leaves. Journal of Ecology 66: 367-383.

Paviani, T. I. 1972. Estudos morfológico e anatômico de Brasilia sickii G. M. Barroso: I. Revista Brasileira de Biologia 32(4): 451-472.

Pridgeon, A. M. 1982. Diagnostic anatomical characters in the Pleurothallidinae (Orchidaceae). American Journal of Botany 69(6): 921-938.

Rasmussen, H. 1981a. The diversity of stomatal development in Orchidaceae subfamily Orchidoideae. Botanical Journal of the Linnean Society 82: 381-393.

Rasmussen, H. 1981b. Terminology and classification of stomata and stomatal development- A critical survey. Botanical Journal of the Linnean Society 83: 199-212.

Salatino, A.; Montenegro, G. \& Salatino, M. L. F. 1986. Microscopia eletrônica de varredura de superfícies foliares de espécies lenhosas do cerrado. Revista Brasileira de Botânica 9: 117-124.

Sass, J. E. 1951. Botanical Microtechnique. 2nd ed. Ames, The Iowa State College Press, Iowa.

Scatena, V. L. \& Menezes, N. L. 1996. Anatomia de escapos e folhas de Syngonanthus Ruhl. (Eriocaulaceae) de campos rupestres. Revista Brasileira de Biologia 56(2): 317-332.

Scatena, V. L. \& Nunes, A. C. 1996. Anatomia de Pleurothallis rupestres Lindl. (Orchidaceae) dos campos rupestris do Brasil. Boletim de Botânica da Universidade de São Paulo 15: 35-43.

Singh, H. 1974. Development and organization of stomata in Orchidaceae. Acta Botanica Indica 9: 94-100.

Stebbins, G. L. \& Khush, G. S. 1961. Variation in the organization of the stomatal complex in the leaf epidermis of Monocotyledons and its bearing on their phylogeny. American Journal of Botany 48: 51-57. 
Stern, W. L.; Morris, M. W. \& Judd, W. S. 1993 b. Comparative vegetative anatomy and systematics Of Spiranthoideae (Orchidaceae). Botanical Journal of the Linnean Society 113: 161-197.

Stern, W. L.; Morris, M. W. \& Judd, W. S. 1997. Vegetative anatomy of subtribe Habenariinae (Orchidaceae). Botanical Journal of the Linnean Society 125: 211-227.

Strasburger, E. 1924. Handbook of Practical Botany. The MacMillan Company, New York.

Wattendorff, J. A. 1976. Third type of raphide crystal in the plant kingdom: Six-sided raphides with laminated sheaths in Agave americana L. Planta 130: 303-311.
Widholzer, C. F. 1993. Morfo-anatomia foliar de espécies do gênero Sophronites Ldl. (Orchidaceae) ocorrentes o Rio Grande do Sul, Brasil. Dissertação de Mestrado. Universidade Federal do Rio Grande do Sul, Porto Alegre.

Wilkinson, H. P. 1979. The plant surface (mainly leaf) In: Metcalfe, C. R. \& Chalk, L. Anatomy of the Dicotyledons. Vol I $2^{\text {nd }} e d$. Oxford Science Publications, Oxford.

Williams, N. H. 1972. The value of plant anatomy. In: In M. Ospina (ed.), Orchid Taxonomy. Proceedings of the $7^{\text {th }}$ World Orchid Conference: 281-288. 